\title{
PENINGKATAN KEMAMPUAN PUKULAN LOB PADA PESERTA UKM BULUTANGKIS STKIP PARIS BARANTAI MELALUI LATIHAN BEBAN RASISTANCE BAND
}

\author{
Jusran $\mathbf{S}^{1}$ \\ Email : jusrankaka04@ gmail.com ${ }^{1}$ \\ ${ }^{1}$ STKIP Paris Barantai
}

\begin{abstract}
Abstrack
Penelitian ini bertujuan untuk mengetahui pengaruh latihan beban rasistance band terhadap peningkatan kemampuan pukulan lob pada pada peserta UKM Buluitangkis STKIP Paris Barantai. Jenis penelitian adalah eksperimen dengan desain "The One Group Pretest-Postest Design". Populasi dalam penelitian ini adalah peserta UKM Buluitangkis STKIP Paris Barantai berjumlah 25 atlet. Teknik sampling menggunakan purposive sampling, dengan kriteria, yaitu: (1) berjenis kelamin perempuan, (2) berusia 18-21 tahun, (3) bersedia menjadi sampel, (4) tidak dalam keadaan sakit, (5) lama latihan minimal 3 bulan, (6) keaktifan 75\%. Berdasarkan kriteria tersebut yang memenuhi berjumlah 16 atlet putri. Instrumen yang digunakan adalah tes kemampuan lob (French Test). Nilai validitas 0,65 dan reliabilitas 0,96 . Analisis data menggunakan uji t taraf signifikansi 5\%. Hasil penelitian menunjukkan bahwa ada pengaruh latihan lempar shuttlecock terhadap peningkatan kemampuan pukulan lob pada pada peserta UKM Buluitangkis STKIP Paris Barantai. Hasil tersebut dapat dibuktikan dengan t-hitung 4,381 > t-tabel 2,13, dan nilai signifikansi $0,001<0,05$, dengan kenaikan persentase sebesar $23,0 \%$.
\end{abstract}

Kata Kunci: Pengaruh; latihan beban rasistance band; pukulan lob

\begin{abstract}
Abstrack
This study aims to determine the effect of rasistance band weight training on increasing the lob ability of the participants of the Badminton UKM STKIP Paris Barantai. This type of research is an experiment with the design of "The One Group Pretest-Postest Design". The population in this study was the participants of the Badminton UKM STKIP Paris Barantai totaling 25 athletes. The sampling technique used purposive sampling, with the following criteria: (1) female, (2) 18-21 years old, (3) willing to be a sample, (4) not sick, (5) minimum exercise duration of 3 months , (6) $75 \%$ activeness. Based on these criteria, there were 16 female athletes who met. The instrument used is the lob ability test (French Test). The validity value is 0.65 and the reliability is 0.96 . Data analysis used t-test with a significance level of 5\%. The results showed that there was an effect of shuttlecock throwing practice on increasing the lob ability of the participants of the STKIP Paris Barantai Badminton UKM. These results can be proven by t-count $4.381>t$-table 2.13, and a significance value of $0.001<0.05$, with a percentage increase of $23.0 \%$.
\end{abstract}

Keywords: Effec; resistance band weight training; lob 


\section{A. Pendahuluan}

Permainan bulutangkis merupakan salah satu cabang olahraga kebangggaan Indonesia, karena cabang olahraga inilah mampu meraih medali emas olimpiade, sehingga prestasi ini harus dipertahankan dan ditingkatkan dimasa mendatang.perlu adanya peran serta masyarakat,lembaga pendidikan dan perkumpulan-perkumpulan bulutangkis ke arah pengembangan dan peningkatan mutu dari cabang olahraga ini,sehingga olahraga bulutangkis dapat membudaya dan menjadi milik bangsa serta menjadi contoh teladan cabang olahraga lainnya di Indonesia.Salah satu usaha untuk mencapai tujuan tersebut dapat dilakukan dengan permainan bulutangkis, karena permainan bulutangkis lebih banyak menuntut kemampuan individu (perorangan) dalam setiap pertandingan yang dilakukan,secara otomatis menuntut ketenangan ,penguasaan emosi dan kecepatan berpikir yang erat kaitannya dengan pembinaan kepribadian. Permainan bulutangkis,terdapat teknik dasar pukulan atas (overhead stroke) maupun pukulan bawah (undehand stroke). Menurut Syahri Alhusin (2007:35), seorang atlet bulutangkis harus mampu menguasai teknik pukulan atas (overhand stroke) maupun pukulan bawah (underhand stroke). banyak lagi jenis pukulan yang harus dikuasai pemain antara lain servis ,lob, dropshot, smash, netting, underhand, dan drive. Dalam permainan bulutangkis terdapat beberapa teknik dasar pukulan yang meliputi : forehand, underhand, overhead clearllob, round the heat, smash, dropshot, netting return smash,backhand overhead, forehand, drive.

Salah satu teknik dalam permainan bulutangkis adalah pukulan lob agar bisa melakukan $l o b$ dengan akurasi yang baik tentu saja tidak lepas dari pembinaan dan latihan yang kontinyu dan terorganisir dengan baik. Pukulan lob atau pukulan panjang merupakan satu keterampilan yang sangat penting dalam permainan bulutangkis setelah servis. Kemapuan ini diperuntukan menyerang kebelakang lapangan lawan. Kelemahan dalam latihan bulutangkis adalah pemain biasanya mengalami kesulitan melakukan pukulan lob sampai jauh ke belakang dan pukulan masih terlalu lemah atau tanggung sehingga memudahkan lawan untuk mengembalikan serta menyerang. Sebaliknya pemain yang terlatih atau atlet akan memiliki kekuatan dan timing yang stabil dalam melakukan pukulan lob .Pukulan lob biasanya dilakukan dengan cara shuttlecock dipukul di depan atas kepala dengan mengayunkan raket ke depan atas dan meluruskan seluruh lengan kemudian lecutkan pergelangan tangan ke depan .Pukulan lob biasanya dilakukan dengan cara shuttlecock dipukul di depan atas kepala dengan mengayunkan raket ke depan atas dan meluruskan seluruh lengan kemudian lecutkan pergelangan tangan ke depan. Pukulan lob dapat dilakukan dari bawah (under head lob) maupun dari atas kepala (overhead lob). Pukulan lob merupakan pukulan yang sangat penting bagi pola pertahanan (defensive) maupun pola penyerangan (offensive). Oleh karena itu pembinaan perlu mengikuti latihan di klub atau perkumpulann (PB).

Pada saat observasi awa di peserta UKM Bulutangkis STKIP Paris Barantai Kotabaru, banyak ditemukan beberapa permasalahan yang dialami siswa, salah satunya teknik pukulan lob, sehingga menimbulkan kesalahan dalam melakukan teknik pukulan lob, terutama pada perkenaan pada shuttlecock kurang tepat, misalnya tangan kurang diluruskan pada saat memukul, bahkan masih ada pemain pada saat melakukan lob, shuttlecock menyangkut net dan bahkan keluar lapangan. Seharusnya pukulan lob dapat menjadi senjata bagi setiap pemain untuk mendapatkan poin atau mematikan lawan.. Pada saat bermain, sebagian besar hasil lob yang dilakukan oleh siswa terlalu melebar ke kanan dan kekiri, sehingga pukulan yang seharusnya menghasilkan poin untuk diri sendiri, justru malah lebih banyak menghasilkan poin untuk lawan. Dari situlah dapat dilihat inti permasalahan yang terdapat di peserta UKM Bulutangkis STKIP Paris Barantai Kotabaru pada permainan bulutangkisnya. Dengan melakukan penelitian di peserta UKM Bulutangkis STKIP Paris Barantai Kotabaru bisa memperbaiki pukulan lob yang kurang menjadi lebih baik lagi dari sebelumnya. Atas 
uraian dari latar belakang masalah di atas, peneliti tertarik untuk mendalami dan meneliti secara ilmiah peningkatan kemampuan $l o b$ dalam bermain bulutangkis.

\section{B. Metode}

Penelitian ini adalah jenis penelitian eksperimen lapangan. Adapun karateritistik penting mengenai penelitian eksperimen. Menurut Sukardi (2009: 180-181) yaitu : (1) variabel bebas yang dimanipulasi, (2) vaiabel lain yang mungkin berpengaruh dikontrol agar tetap konstan, dan (3) efek atau pengaruh manipulasi variabel bebas dan variabel terikat diamati secara langsung oleh peneliti. Eksperimen merupakan suatu penelitian yang dengan sengaja peneliti melakukan manipulasi terhadap satu atau lebih variabel dengan suatu cara tertentu sehingga berpengaruh pada satu atau lebih variabel lain yang di ukur. Lebih lanjut dijelaskan, variabel yang dimanipulasi disebut variabel bebas dan variabel yang akan dilihat pengaruhnya disebut variabel terikat. Melihat dari berbagai pendapat para ahli di atas dapat disimpulkan penelitian eksperimen adalah suatu penelitian yang berusaha melihat pengaruh sebab akibat dari satu atau lebih variabel independen dengan satu atau lebih variabel kontrol. Penelitian ini termasuk quasi experiment. Desain yang digunakan dalam penelitian ini adalah "The Group Pretest Postest Design " atau tidak adanya control (Sukardi, 2009: 18). Metode experiment dengan sampel tidak terpisah maksudnya peneliti hanya memiliki satu kelompok saja, yang diukur dua kali, pengukuran pertama (pretest) dilakukan sebelum subjek diberi perlakuan, kemudian perlakuan (treatment), yang akhirnya ditutup dengan pengukuran kedua (posttest). Menurut Sugiyono (2013:55) populasi adalah wilayah generalisasi yang terdiri atas terdiri atas objek atau subjek yang mempunyai kuantitas dan karakteristik tertentu yang ditetapkan oleh peneliti untuk dipelajari dan kemudian disimpulkan. Populasi adalah keseluruhan subjek penelitian (Suharsimi Arikunto, 2006:115). Populasi dalam penelitian ini adalah peserta UKM bulutangkis STKIP Paris Barantai Kotabaru yang akan diteliti sebanyak 16 peserta putri. sedangkan Pengertian sampel menurut Kusumawati M. (2015:94) adalah sebagian dari jumlah populasi yang di pilih untuk sumber data. Sedangakan Pengertian sampel menurut. Menurut Gunawan (2013:2) yang di maksud sampel adalah sebagian atau wakil populasi di teliti atau cara sederhana sampel panelitian adalah sebagian dari populasi yang di ambil sebagai sumber data dan dapat mewakili seluruh populasi. Berpijak pada beberapa pendapat para ahlli diatas maka Penarikan sampel tersebut maka peneliti menentukan sampel penelitian dengan memnggunakan Purposive Sampling.

Menurut Sugiyono (2017) purposive sampling yaitu teknik pengambilan sampel data yang didasarkan pada pertimbangan tertentu. Subjek dan objek penelitian yang telah ditentukan oleh peneliti. teknik sampling ini yang cukup sering digunakan. Metode ini menggunakan kriteria yang telah dipilih oleh peneliti dalam memilih sampel. Kriteria pemilihan sampel terbagi menjadi kriteria inklusi dan eksklusi. Kriteria inklusi merupakan kriteria sampel yang diinginkan peneliti berdasarkan tujuan penelitian. Sedangkan kriteria eksklusi merupakan kriteria khusus yang menyebabkan calon responden yang memenuhi kriteria inklusi harus dikeluarkan dari kelompok penelitian. Berdasarkan kriteria tersebut yang memenuhi berjumlah 16 peserta putri UKM Bulutangkis STKIP Paris Barantai. Penelitian ini menggunakan treatment atau perlakuan berupa latihan beban rasistance band untuk mengetahui peningkatan kemampuan pukulan lob atlet bulutangkis, dengan frekuensi perlakuan sebanyak 14 kali. Sebelum perlakuan tersebut diberikan pretest dengan menggunakan tes kemampuan lob, kemudian diberikan perlakuan berupa latihan beban rasistance band dengan lempar shuttlecock, sesudah itu dites kembali/diberi posttest dengan tes yang sama. Hasil yang diperoleh dari kelompok tersebut, kemudian dibandingkan antara pre-test dengan posttest yang selanjutnya dianalisis dengan menggunakan uji-t. Sebelum melangkah ke uji-t, ada persyaratan yang harus dipenuhi oleh peneliti bahwa data yang dianalisis harus berdistribusi normal, untuk itu perlu dilakukan uji normalitas dan uji homogenitas (Suharsimi Arikunto, 2006:299). Teknik analisis data disesuaikan dengan 
pertanyaan dan hipotesis penelitian. Pertanyaan dan hipotesis yang diajukan dalam penelitian ini sesuai dengan analisis statistika deskriptif dan anlisis inferensial. Data yang dikumpulkan tersebut akan dianalisis secara statistik deskriptif maupun inferensial untuk keperluan pengujian hipotesis penelitian. Adapun gambaran yang akan digunakan dalam penelitian ini sebagai berikut:

1. Statistik deskriptif, memberikan gambaran umum tentang rata (mean), standar deviasi (sd), nilai minimum dan nilai maksimum.

2. Statistik inverensial, menguji hipotesis penelitian dengan uji T-test Secara keseluruhan analisis data statistik yang digunakan pada umumnya menggunakan sistem komputer pada program SPSS versi 22 pada taraf signifikansi $\alpha=0,05(95 \%)$.

\section{Hasil dan Pembahasan}

Table.1. Hasil analisis deskriptif data hasil pukulan lob

\begin{tabular}{cccccc} 
Tes & $\mathrm{N}$ & Hasil & Hasil & Mean & SD \\
& & & & \\
& & Terendah & Tertinggi & & \\
\hline Pre test & 16 & 12 & 65 & 39,44 & 17,709 \\
Post test & 16 & 22 & 89 & 51,06 & 22,059 \\
\hline
\end{tabular}

Dari tabel di atas dapat diketahui bahwa data pretest memiliki rata-rata (mean) hasil 39,44 nilai terendah 12, nilai tertinggi 65 dan (stand daviation) 17,709 sedangkan data posttest rata-rata (mean) 51,06, nilai terendah 22, nilat tertinggi 89 dan (stand daviation) 22,059 .

Table. 2. Tingkat presentase preetets pukulan lob

\begin{tabular}{rccc} 
Skor Baku & Kategori & Frekuensi & Presesntase \\
\hline 74,2 ke atas & Baik Sekali & 0 & $0 \%$ \\
65,7 sd 74,1 & Baik & 0 & $0 \%$ \\
57,2 sd 65,6 & Sedang & 4 & $25,0 \%$ \\
48,7 sd 57,1 & Kurang & 0 & $0 \%$ \\
48,6 ke bawah & Kurang Sekali & 12 & $75,0 \%$ \\
\hline Jumlah & & 16 & $100 \%$
\end{tabular}

Terdapat 4 peserta $(25,0 \%)$ memiliki kemampuan pukulan lob bulutangkis dalam kategori sedang, sedangkan terdapat 12 peserta $(75,0 \%)$ memiliki pukulan lob bulutangkis dalam kategori kurang sekali

Table. 3. Tingkat presentase posttets pukulan lob pada

\begin{tabular}{rccc} 
Skor Baku & Kategori & Frekuensi & Presesntase \\
\hline 74,2 ke atas & Baik Sekali & 2 & $12,5 \%$ \\
65,7 sd 74,1 & Baik & 4 & $25,0 \%$ \\
57,2 sd 65,6 & Sedang & 1 & $6,3 \%$ \\
48,7 sd 57,1 & Kurang & 1 & $6,3 \%$ \\
48,6 ke bawah & Kurang Sekali & 8 & $50,0 \%$ \\
\hline Jumlah & & 16 & $100 \%$
\end{tabular}


Terdapat 2 peserta $(12,5 \%)$ memiliki kemampuan pukulan lob bulutangkis dalam kategori baik sekali, sedangkan terdapat 4 peserta $(25,0 \%)$ baik, selanjatnya terdapat 1 peserta $(6,3 \%)$ memiliki kemampuan pukulan lob bulutangkis dalam kategori sedang, terdapat 1 peserta $(6,3 \%)$ memiliki kemampuan pukulan lob bulutangkis dalam kategori kurang, dan terdapat 8 peserta $(50,0 \%)$ memiliki kemampuan pukulan lob bulutangkis dalam kategori kurang sekali

Table. 4. Rangkuman uji normalitas data peningkatan pukulan lob

\begin{tabular}{cccc} 
Tes & Statistic & df & Signifikan \\
\hline Pre test & .934 & 18 & .278 \\
Post test & .924 & 18 & .198 \\
\hline
\end{tabular}

Berdasarkan tabel di atas tentang hasil uji normalitas data pukulan lob pada peserta UKM Bulutangkis STKIP Pasir Barantai dapat dikemukakan sebagai berikut :

1. Data tes awal hasil kemampuan pukulan lob pada pesesrta UKM Bulutangkis SRKIP Paris Barantai diperoleh tingkat kolmorgov-smirnof sebesar 0.934, sedangkan tingkat signifikan 0.278 Lebih besar dari pada $\alpha 0,05$. Hal ini menunjukkan bahwa data tes awal hasil kemampuan pukulan lob pada pesesrta UKM Bulutangkis SRKIP Paris Barantai berdistribusi normal.

2. Data tes akhir hasil hasil kemampuan pukulan lob pada pesesrta UKM Bulutangkis SRKIP Paris Barantai diperoleh tingkat kolmorgov-smirnof sebesar 0.924, sedangkan tingkat signifikan 0.198 lebih besar dari pada $\alpha$ 0,05. Hal ini menunjukkan bahwa data kemampuan pukulan lob pada pesesrta UKM Bulutangkis SRKIP Paris Barantai berdistribusi normal.

Table. 5. Rangkuman uji homogenitas data peningkatan pukulan lob

$$
\begin{array}{llll}
\text { Hasil pukulan lob } \quad \text { Levene Statistik } & \text { df1 } & \text { df2 }
\end{array}
$$

\begin{tabular}{crrrr}
\hline & & & & \\
Hasil & 1.645 & 1 & 30 & 0.209 \\
\hline
\end{tabular}

Berdasarkan Tabel hasil uji homogenitas data hasil pukulan lob bulutangkis dengan Levene Test adalah 1.645 Dengan signifikansi 0.209 Karena nilai signifikan lebih besar dari $\alpha$ 0,05. Maka data hasil pukulan 1;ob bulutangkis peserta UKM Bulutangkis STKIP Paris Barantai adalah homogen.

Table. 6. Rangkuman uji analsisi datainferensial (uji-t) data peningkatan pukulan lob

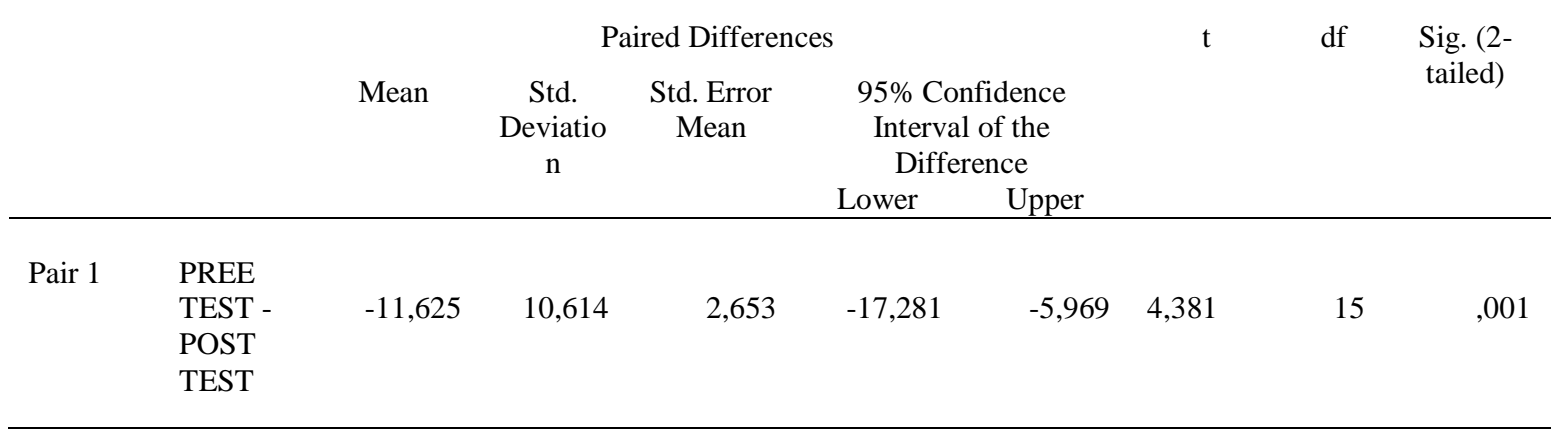


Dari hasil uji-t yang didapat dari analisis data menggunakan SPSS 22.00 dapat dilihat bahwa t hitung 4,381 dan t table 2,13 dengan nilai signifikan p sebesar 0,001 oleh karena itu dari analisis tersebut dapat disimpulkan bahwa nilai t 4,381 > t tab 2,13 dan nilai p (sig) $0,001<0,05$, maka hasil ini menujukan bahwa ada pengaruh yang signifikan dalam penerapan latihan lempar shuttlecock terhadap peningkatan pukulan lob pada pesereta UKM Bulutangkis STKIP Paris Barantai. Berdasarkan hasil ini maka hipotesis alternatif (Ha) diterima. Hasil selengkapnya disajikan pada table 7 di bawah ini

Table. 7. Uji Hipotesis data pree test dan post test

\begin{tabular}{lllllll} 
Kelompok & Rata-rata & \multicolumn{5}{c}{ t-test for Equalty of means } \\
\cline { 3 - 6 } & & t ht & t tb & Sig & Selisish & $\%$ \\
\hline Preetest & 39,44 & 4,381 & 2,13 & 0,001 & 11,62 & $23,0 \%$ \\
Posttest & 51,06 & & & & & \\
\hline
\end{tabular}

Dari hasil uji-t dapat dilihat bahwa t hitung 4,381 dan t tabel 2,13 (df 15) dengan nilai signifikansi p sebesar 0,001. Oleh karena t hitung 4,381 > ttabel 2,13, dan nilai signifikansi $0,001<0,05$, maka hasil ini menunjukkan terdapat perbedaan yang signifikan. Dengan demikian hipotesis alternatif $(\mathrm{Ha})$ yang berbunyi "ada pengaruh latihan lempar shuttlecock terhadap peningkatan pukulan lob pada peserta UKM bulutangkis putri STKIP Paris Barantai", diterima. Artinya latihan lempar shuttlecock memberikan pengaruh yang signifikan terhadap peningkatan pukulan lob pada peserta UKM bulutangkis putri STKIP Paris Barantai. Dari data pretest memiliki rerata 39,44, selanjutnya pada saat posttest rerata mencapai 51,05. Besarnya peningkatan pukulan lob tersebut dapat dilihat dari perbedaan nilai rata-rata yaitu sebesar 11,62, dengan kenaikan persentase sebesar 23,0\%.

Pembahasan

Dari hasil statistik menunjukkan bahwa peserta UKM bulutangkis putri STKIP Paris Barantai yang mengikuti latihan lempar shuttlecock selama 12 kali pertemuan mengalami peningkatan pukulan lob pada permainan bulutangkis. Dengan mengikuti proses latihan selama 16 kali sudah termasuk pretest dan posttest maka dapat dikatakan terlatih, hal tersebut dapat dibuktikan dengan ada perubahan yang menetap. Dalam memberikan program latihan beban rasistance band melempar shuttlecock dengan berbagai macam variasi, tentunya peserta UKM bulutangkis putri STKIP Paris Barantai pemula lebih dapat berkembang lagi. Peningkatan pukulan lob sebelum dan sesudah diberikan treatment terdapat selisih perbedaan yang sangat signifikan dengan selisih rerata. Dari data yang sudah diperoleh, hasil pretest dan posttest terdapat . peningkatan yang signifikan. Dari hasil penelitian menunjukkan bahwa selisih mean antara pretest dan posttest atlet bulutangkis putri setelah mengikuti program latihan beban rasistance band melempar shuttlecock sebanyak 14 kali pertemuan dapat menunjukkan peningkatan terhadap pukulan lob dalam permain bulutangkis pada peserta UKM bulutangkis putri STKIP Paris Barantai. Dengan demikian hipotesis yang berbunyi "Ada pengaruh latihan beban rasistance band melempar shuttlecock terhadap peningkatan kemampuan pukulan lob pada peserta UKM bulutangkis putri STKIP Paris Barantai”, diterima. Artinya latihan beban rasistance band melempar shuttlecock memberikan pengaruh yang signifikan terhadap peningkatan kemampuan pukulan lob pada peserta UKM bulutangkis putri STKIP Paris Barantai. Menurut Djoko Pekik Irianto (2002: 11), latihan adalah suatu proses mempersiapkan organisme atlet secara "sistematis" untuk mencapai mutu prestasi maksimal dengan diberi beban fisik dan mental yang teratur, terarah, meningkat, dan 
"berulang-ulang" waktunya. Sistematis tersebut di atas artinya proses pelatihan dilaksanakan secara teratur, terencana menggunakan pola dan sistem tertentu, metodis, berkesinambungan dari sederhana menuju yang komplek, dari yang mudah ke yang sulit, dari yang sedikit ke yang banyak, dan sebagainya. Sedangkan berulang-ulang yang dimaksudkan di atas artinya setiap gerak harus dilatih secara bertahap dan dikerjakan berkali-kali agar gerakan yang semula sukar dilakukan, kurang koordinatif menjadi semakin mudah, otomatis, reflektif gerak menjadi efisien. Menurut pernyataan diatas tentunya pelatih agar dapat memahami tujuan ataupun sasaran dari pemberian latihan pada anak. Waktu latihan yang relatif pendek hanya dapat menyebabkan perubahan akibat latihan yang bersifat sementara dan akan mudah sekali kembali pada keadaan semula. Namun, waktu latihan yang relatif lama akan menyebabkan terjadinya perubahan akibat latihan yang bersifat tetap dan tidak bersifat sementara. Kemampuan pukulan lob pada peserta UKM bulutangkis putri STKIP Paris Barantai dapat meningkat apabila latihan dilakukan secara terprogram, terencana, dan dilakukan dengan benar. Penelitian yang telah dilakukan dengan pemberian latihan beban rasistance band melempar shuttlecock terbukti dapat meningkatkan kemampuan pukulan lob pada peserta UKM bulutangkis putri STKIP Paris Barantai.

\section{Simpulan}

Berdasarkan data hasil penelitian dapat disimpulkan bahwa ada pengaruh latihan beban rasistance band lempar shuttlecock terhadap peningkatan kemampuan pukulan lob pada peserta UKM bulutangkis putri STKIP Paris Barantai. Hasil tersebut dapat dibuktikan dengan t hitung 4,381 > ttabel 2,13, dan nilai signifikansi $0,001<0,05$, dengan kenaikan persentase sebesar $23,0 \%$.

\section{Daftar Pustaka}

Bimantara, Y., \& Purnomo, M. (2019). Pengaruh Latihan Resitance Band Leg Press Dan Resistance Band Lying Leg Press Terhadap Kekuatan Otot Tungkai. Jurnal Prestasi Olahraga, 2(1).

Ervi, E., Kesoema, T. A., \& Novriansyah, R. (2020). Efek Prehabilitation Exercise dengan Resistance Band terhadap Kekuatan Otot Kuadrisep Femoris pada Pasien Total Knee Replacement. Medica Hospitalia: Journal of Clinical Medicine, 7(1), 46-52.

Imam Gunawan, 2013. metode penelitian kualitatif : teori praktik . Jakarta: Bumi Aksar

Ismayawati, D. (2016). Pengaruh Latihan Resistance Band Terhadap Keterampilan Smash Permainan Bolavoli Ditinjau Dari Tinggi Badan. Artikel Tesis.

Jannah, S., \& Purnomo, M. (2018). Pengaruh Latihan Overhead Tricep Extension Resistance Band Dan Overhead Tricep Extension Dumbell Terhadap Power Lengan. Jurnal Prestasi Olahraga, 1(4).

Kusumawati, M. (2015). Penelitian Pendidikan PENJASORKES. Bandung: Alfabeta

Lestari, A., \& Nasrulloh, A. (2018). Efektivitas Latihan Body Weight Training dengan dan Tanpa Menggunakan Resistance Band terhadap Penurunan Berat Badan dan Persentase Lemak. MEDIKORA, 17(2), 91-101.

Liskhardinanda, M. V., \& Kusuma, I. D. M. A. W. (2021). Pengaruh Latihan Resistance Band 75lbs dan 45lbs Terhadap Power Otot Tungkai SMAN 1 Taman Sidoarjo. Jurnal Prestasi Olahraga, 4(7), 94-101.

Nebahatqoru, M., Sagitarius, S., Purnamasari, I., \& Novian, G. (2021). Enam minggu latihan resistance band untuk meningkatkan power tendangan atlet taekwondo poomsae. Multilateral: Jurnal Pendidikan Jasmani dan Olahraga, 20(3), 215-244.

Ningrum, R. S. (2020). Pengaruh Latihan Resistance Band dan Leg Banding Terhadap Peningkatan Kecepatan Tendangan Samping (Cechuitui) Pada Ekstrakurikuler MAN 2 Mojokerto. Jurnal Prestasi Olahraga, 3(1). 
Rosyida, C. (2017). Efektivitas Latihan Beban Metode De Lorme Dengan Metode Oxford Terhadap Peningkatan Kekuatan Otot Biceps Brachii Pada Pemain Bulutangkis Man 1 Malang (Doctoral dissertation, University of Muhammadiyah Malang).

Rohmah, M. Q., \& Purnomo, M. (2018). Pengaruh Latihan Chest Press Resistance Band Dan Push Up Terhadap Kekuatan Otot Lengan Mahasiswa Universitas Negeri Surabaya. Jurnal Prestasi Olahraga, 1(4).

Sugiyono. (2012). Statistik untuk penelitian. Bandung: Alfabeta

-------, (2013). Metode Penelitian, Bandung: CV.ALFABETA

Sugiyono. (2007). Metode Penelitian Kuantitatif, Kualitatif, dan R\&D. Bandung:Alfabeta.

Suharsimi Arikunto. (2006). Prosedur Penelitian Suatu Pendekatan Praktik. Jakarta: Rineka Cipta.

Sukardi. (2009). Evaluasi Pendidikan. Jakarta: Bumi Aksara.

Syahri Alhusin. (2007). Gemar Bermain Bulutangkis. Direktorat Jendra Pendidikan Dasar dan Menengah.

Sari Nadeak, M. A., Sukendro, S., \& Endarman, E. (2020). Pengaruh Resistance Band Exercises Terhadap Peningkatan Hasil Lari 100 Meter Siswa Kelas Vii Smp Negeri 30 Muaro Jambi. Pengaruh Resistance Band Exercises Terhadap Peningkatan Hasil Lari 100 Meter Siswa Kelas Vii Smp Negeri 30 Muaro Jambi.

Sari Nadeak, M. A., Sukendro, S., \& Endarman, E. (2020). Pengaruh Resistance Band Exercises Terhadap Peningkatan Hasil Lari 100 Meter Siswa Kelas Vii Smp Negeri 30 Muaro Jambi. Pengaruh Resistance Band Exercises Terhadap Peningkatan Hasil Lari 100 Meter Siswa Kelas Vii Smp Negeri 30 Muaro Jambi.

Tarihoran, D., \& Mahmuddin, M. (2021). Kontribusi Latihan Hand Grip Dan Latihan BackUp Terhadap Servis Slice Pada Atlet Putra Komunitas Tenis Lapangan Unimed. Jurnal Prestasi, 4(2), 66-71.

Winoto, G. S. E. (2009). Perbedaan Metode Latihan Forehand Drive Antara Metode Tiga Tahap dan Metode global Terhadap Kemampuan Forehand Drive Pada Petenis Klub Diklat Semarang Tahun 2009 (Doctoral dissertation, Universitas Negeri Semarang). 